
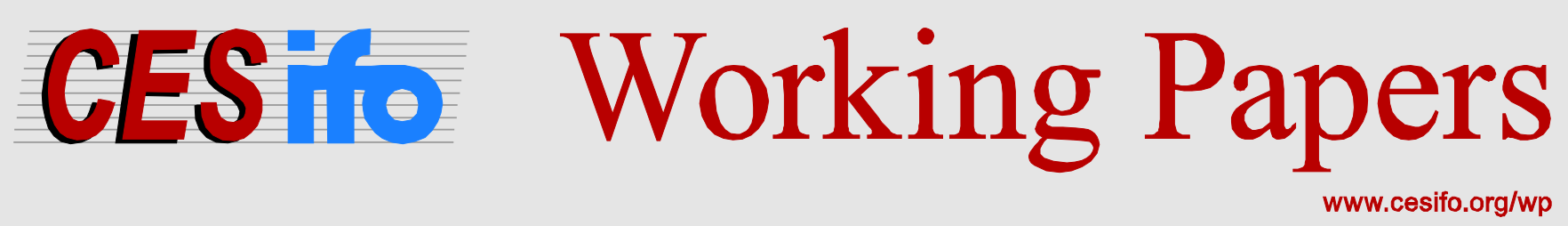

\title{
Optimal Timing in Rotten Kid Families
}

\author{
João Ricardo Faria \\ Emilson Caputo Delfino Silva
}
CESIFO WORKING PAPER No. 6333
CATEgORY 1: Public FinANCE
JANUARY 2017

An electronic version of the paper may be downloaded

- from the SSRN website: Www.SSRN.com

- from the RePEc website: $\quad$ www.RePEc.org

- from the CESifo website: www.CESifo-group.org/wp 


\title{
Optimal Timing in Rotten Kid Families
}

\begin{abstract}
In a family context with endogenous timing, multiple public goods and alternative parental instruments, we show that the optimal timing for the sequential-action game played by rotten kids and a parent depends crucially on whether the kids are homogeneous or heterogeneous. For homogeneous kids, the rotten kid theorem holds irrespective of the parental policy instrument, implying that it is optimal to let the kids to be action leaders. If the kids are heterogeneous, however, parental leadership yields a first best outcome and, hence, it is optimal whenever the kids are economically dependent and agree on the tradeoff between public goods.
\end{abstract}

JEL-Codes: D130, D610, D640, D780, H410.

Keywords: rotten kids, public goods, endogenous timing, heterogeneous preferences, economically dependent.

João Ricardo Faria

IPED, University of Texas at El Paso

USA - El Paos, TX

rfaria2@utep.edu
Emilson Caputo Delfino Silva

Department of Marketing, Business

Economics \& Law, University of Alberta

Canada-Edmonton, $A B$

emilson@ualberta.ca 


\section{Introduction}

In the well-known family setting in which Becker's (1974, 1976, 1977, 1981) rotten kid theorem holds, the benevolent parent and her rotten kids play a two-stage game where the kids are leaders and the parent is a follower. Such a setting surely captures the essence of many family interactions. In the family's sequential-action game, the kids find it desirable to take actions that maximize their parent's welfare, internalizing all externalities that arise within the family. In other commonly observable family interactions, however, the parent behaves as a leader vis-à-vis her children in the sequential-action game. This paper examines circumstances under which it is optimal for the family that a parent plays a leadership role in her interactive actions with her kids. ${ }^{1}$ In doing so, we also describe circumstances where it is rational for the parent to be a follower. ${ }^{2}$

It is rational for a parent to be a follower if, by being so, her welfare is maximized. Bergstrom (1989) shows that rotten kids maximize their loving parent's welfare if the kids' utilities are conditionally transferable and the parent views her kids as normal goods. Cornes and Silva (1999) extends the set of circumstances under which the rotten kid theorem holds. It includes settings in which homogeneous kids (who possess identical preferences) consume normal goods and contribute to a pure public good. Cremer and Roeder (2017) shows that the rotten kid theorem obtained by Cornes and Silva (1999) also holds in an interfamily context, where the rotten kids belong to two separate families, but form a family of their own through marriage. Interestingly, in equilibrium, all players enjoy the same utility level despite differences in initial incomes between the kids’ parents. Chiappori and Werning (2002) clearly demonstrates that the rotten kid theorem breaks down in the setting considered by Cornes and Silva (1999) if the kids are heterogeneous. ${ }^{3}$

\footnotetext{
${ }^{1}$ When considering parental leadership, we are not simply assuming that the parent can precommit to an action that immediately yields her most preferred outcome in the game played with her kid. Such a benefit of precommitment for the parent is present in the Samaritan's dilemma (Buchanan (1975)). Gintis (2009) (see also Bruce and Waldman (1990)) models the Samaritan's dilemma in a two-period setting where a kid saves part of her income in the first period and receives a transfer from her father in the second period. Her father has an altruistic feeling toward his daughter. He saves in the first period in order to give a transfer to his daughter in the second period. In this game the kid is the leader, and the parent is the follower. In equilibrium, the kid saves too little and her father has to make a large transfer. If the father can precommit to a transfer level, both he and her daughter would be better off. The Samaritan's dilemma yields an inefficient allocation. See, e.g., Thompson (1980), Kotlikoff (1987) and Coate (1995) for further discussion of the Samaritan's dilemma.

${ }^{2}$ Optimal timing in Stackelberg games have been investigated in the industrial organization literature. See, e.g., Gale-Or (1985), Dowrick (1986), Hamilton and Slutsky (1990), and Amir and Stepanova (2006). Unlike these papers, we consider settings where leader(s) and follower(s) control different types of actions and the players who contribute to public goods may be heterogeneous.

${ }^{3}$ The rotten theorem also fails in models that consider leisure choice (e.g., Bergstrom (1989)), when individuals choose between present and future consumption (Lindbeck and Weibull (1988), Bruce and Waldman (1990)) and
} 
On the other hand, one can clearly envision a standard situation where it is always optimal for the parent to be a family leader. This corresponds to a setting where the parent is a benevolent dictator, able to command and control the allocation of resources within the family, including all kids' actions. This is not, however, what we have in mind. We consider a parent who has limited power to implement her most desirable allocation: the parent does not control her kids' actions.

It seems logical to think that the extent to which a parent (leader or follower) is able to control her family's allocation varies, among other things, with her kids' degree of economic dependence. For kids who are completely dependent, their consumption of a basket of private goods (food, clothing, etc.) typically depends exclusively on consumption amounts determined by their parent. Kids who are economically independent, on the other hand, do not face this constraint. A parent may need to resort to income transfers or bequests to attempt influencing consumption and hence behavior of her economically independent kids. To the best of our knowledge, all theoretical papers in the literature assume that the kids possess some initial income and the way that the parent may influence their behavior is through income transfers. In our analysis, we consider this case as well but assume that this situation occurs for economically independent kids only (who earn their own income outside the family). Alternatively, we also consider economically dependent kids, who have no initial income. In this situation, the family income belongs to the parent who fully determines each kid's private-good consumption level. ${ }^{4}$

Some recent papers have examined voluntary contribution games to multiple public goods in family and other contexts (see, e.g., Cornes and Itaya (2010), Cornes, Itaya and Tanaka (2012), Silva (2014), Silva (2016), Silva and Lucas (2016)). The motivation for the analysis in family settings is clear, since kids (and parents) contribute to several public goods (e.g., housework, run errands for the parent, doing good deeds to local community to augment family reputation, etc.) within their family. Hence, we should also consider voluntary provision of multiple public goods within families.

In this paper, we build on the model advanced by Cornes and Silva (1999). We include an extra public good, and analyze sequential games (denoted ‘supergames') with endogenous timing.

when families make discrete choices (Lundberg and Pollak (2003)). For good surveys on this topic, see Bergstrom (2008) and Lafferrere and Wolff (2006).

${ }^{4}$ We are aware that these two polar cases do not capture all possible situations. There are situations where the kids earn some income, but are still economically dependent on their parents. For simplicity, we ignore these situations. 
Every supergame has three stages. In the first stage, the parent chooses the timing for the subsequent sequential-action game. The chosen sequential-action game occurs in the second and third stages. In any sequential-action game, the kids' actions are their contributions to the public goods. The parent's actions are either her choices of income transfers (for economically independent kids) or her choices of kids’ private-good consumption levels (for economically dependent kids). There are two possible timings for the sequential-action game: parental leadership (with kids being followers) and kids' leadership (with the parent being a follower). We shall refer to these sequential-action games as the Parental Leadership Game (PLG) and the Kids’ Leadership Game (KLG), respectively.

The equilibrium concept is Subgame Perfect Nash Equilibrium (SPNE). Utilizing backward induction, we first determine the SPNE for the PLG and the SPNE for the KLG. Later, we determine the SPNE for the supergame by comparing the family welfare levels produced by the SPNE for the PLG and the SPNE for the KLG. The SPNE for the supergame includes the optimal timing decision made by the parent in the first stage of the supergame as well as the optimal, time-consistent, actions of parent and kids.

Heterogeneity in preferences plays a key role in our analysis. As we demonstrate in what follows, the SPNE for the PLG is first best if the parent controls each kid's private-good consumption and all kids provide positive amounts of both public goods. In such circumstances, parent leadership in the sequential-action game is optimal for the family. This result, however, depends crucially on a restriction that is necessary for an equilibrium with positive contributions to public goods by all kids. The kids must agree on the tradeoff between the two public goods; namely, they must have identical marginal rates of substitution between public goods. Although this assumption appears to be quite limiting, it is a fundamental piece that supports a commonly observable phenomenon in families where the parent is the action leader. In such families, typically, all kids make positive contributions to all public goods.

This paper produces several important results, the most important of which are as follows. We show that the optimal timing may vary depending on whether the kids are homogeneous or heterogeneous. When the kids are homogeneous, the rotten kid theorem holds under both parental control of income transfers and parental control of each kid's consumption of the private good. Parental leadership in the sequential-action game yields a first best outcome only when the parent 
controls the kids' private-good consumption. ${ }^{5}$ Hence, for economically independent kids, it is optimal to let the kids to be action leaders. For economically dependent kids, the choice of timing is irrelevant because action leadership by either parent or kids produces a first best outcome.

When the kids are heterogeneous, the optimal timing decision may vary according to whether the kids are economically dependent. If the kids are economically dependent, it is always optimal to let the parent to be the action leader. As we mentioned above, parental leadership in the sequential-action game under such circumstances yields a first best outcome. If the kids are economically independent, however, parental leadership in the sequential-action game may not be optimal because it never produces a first best outcome. Action leadership by kids is also inefficient (see the discussion below for more details), but it may dominate parental leadership if the kids are nearly homogeneous. If the kids are sufficiently heterogeneous, parental leadership in the sequential-action game dominates even when the kids are economically independent.

Action leadership by kids is inefficient if the kids are heterogeneous because the sole provider of public goods in this context is the kid who has the highest marginal rates of substitution for the public goods. This kid acts as a non-benevolent dictator, since the equilibrium allocation reflects his most preferable choices. Nevertheless, one can say that this kid emerges endogenously as the natural leader among his siblings. By invoking revealed preference, one concludes that his siblings, by providing nothing, agree that the kid who has the highest demands for public goods should lead the family in terms of public good provision. This is a remarkable result. It contributes to two branches of literature: (i) family economics; and (ii) leading by example. ${ }^{6}$ As far as we know, this is the first paper that examines the SPNE in a family context where heterogeneous kids are action leaders, and who provide multiple public goods.

Our main contribution to the leading by example literature follows from the fact that the rationale underlying the emergence of a natural leader in our case is at odds with the rationale underlying the game-theoretic predictions of this literature. Our result derives its rationale from

\footnotetext{
${ }^{5}$ When parents are action leaders and make income transfers, the income redistribution is policy neutral in the sense that it does not affect the overall quantities of public goods provided by the kids. On policy neutrality results for games involving provision of one pure public good, see, e.g., Warr (1983), Caplan, Cornes and Silva (2000) and Cornes and Itaya (2010).

${ }^{6}$ Wagner (1965) suggests that leaders who recognize the potential for welfare improvements may undertake convincing actions that cause others to act collectively toward their mutual benefit without the need for punishment, pressure groups, or rent seeking. Kindleberger (1981) argues that hegemonic power is not necessary for successful leadership in providing international public goods. It is possible for groups of smaller nations to serve successfully as examples through initiatives concerning foreign aid, peacekeeping, etc. Arce (2001) provides several illustrations of the success of leading by example (see also the articles contained in Tuchman Matthews (1991)).
} 
heterogeneous preferences while the leading-by-example strategy, in which the leader commits to a small initial contribution and later matches larger contributions by other players, may be optimal in a matching game with homogeneous players. Arce (2004) demonstrates that a leading-byexample strategy can implement the cooperative outcome. ${ }^{7}$

The remainder of the paper is as follows. Section 2 introduces the basic model and derives the parent's most preferable allocation (first best). Sections 3 and 4 examine the supergame for homogeneous and heterogeneous kids, respectively. Section 5 offers concluding remarks.

\section{Basic Model}

Consider a family with a benevolent parent and $n \geq 2$ rotten kids. Kid $i, i=1, \ldots, n$, derives utility $u^{i}\left(c_{i}, G, Q\right)$ from consumption of $c_{i}$ units of numeraire good, $G$ units of a pure public good and $Q$ units of another pure public good, where $G=\sum_{i=1}^{n} g_{i}, Q=\sum_{i=1}^{n} q_{i}$ and $g_{i}$ and $q_{i}$ denote kid $i$ 's contributions to the public goods. ${ }^{8}$ We assume that $u^{i}$ is increasing at a decreasing rate in each argument, concave and strongly separable. In order to provide intuition and facilitate comparisons, we will often let $u^{i}=\alpha_{i} \ln c_{i}+\beta_{i} \ln G+\left(1-\alpha_{i}-\beta_{i}\right) \ln Q$, where $\alpha_{i}>0, \beta_{i}>0$ and $1>\alpha_{i}+\beta_{i}$. The parent is benevolent and utilitarian. Her utility function is $W=\sum_{j=1}^{n} u^{j}$.

Let us first examine the parent's most preferred allocation. We shall refer to this allocation as 'first best' throughout. We assume that it takes one unit of private good to produce one unit of each public good. Let $Y>0$ denote the family's income level. The family's resource constraint is

$$
\sum_{j=1}^{n}\left(c_{j}+g_{j}+q_{j}\right)=\sum_{j=1}^{n} c_{j}+G+Q=Y .
$$

The parent chooses non-negative $\left\{c_{1}, \ldots, c_{n}, G, Q\right\}$ to maximize $W=\sum_{j=1}^{n} u^{j}$ subject to (1). Let $\lambda \geq 0$ denote the Lagrangian multiplier associated with this constraint. Since the objective function is

\footnotetext{
${ }^{7}$ Oliveira et al. (2005) investigates how one can produce cooperative behavior in an evolutionary game where the players are non-cooperative. The paper shows that leading by example is more likely to succeed the greater the degree of concavity (curvature) of the public benefit function. Leading by example is neutrally stable if this function has a sufficiently low degree of concavity.

${ }^{8}$ We use superscripts to denote functions.
} 
concave and the constraint is linear, the first order conditions are necessary and sufficient for a constrained maximum. The first order conditions are as follows for $i=1, \ldots, n:^{9}$

$$
\begin{aligned}
& u_{c}^{i}=\lambda \Rightarrow u_{c}^{i}=u_{c}^{j}, \quad j=1, \ldots, n, j \neq i, \\
& \sum_{i=1}^{n} u_{G}^{i}=\lambda \\
& \sum_{i=1}^{n} u_{Q}^{i}=\lambda .
\end{aligned}
$$

Conditions (2) inform us that the parent allocates consumption of private good in order to equate the marginal utilities of private-good consumption. Combining conditions (2) with conditions (3) and (4), one at a time, yields the following Samuelson conditions for optimal provision of the public goods:

$$
\begin{aligned}
& \sum_{i=1}^{n} \frac{u_{G}^{i}}{u_{c}^{i}}=1 . \\
& \sum_{i=1}^{n} \frac{u_{Q}^{i}}{u_{c}^{i}}=1 .
\end{aligned}
$$

The first best satisfies conditions (1), (2), (5) and (6).

\section{Supergame with Homogeneous Kids}

In this section, we assume that the kids are homogeneous; that is, $u^{i}=u\left(c_{i}, G, Q\right), \forall i$. We start by examining the situation in which the parent controls income transfers.

\subsection{Parent controls income transfers}

Let $y_{i}>0$ denote the initial income of kid $i$. Since the kids have identical utilities, we assume that the motivation for the parent's income transfers comes from the fact that the kids possess different initial income levels. There is no loss in generality in assuming that $y_{h}>y_{h+1}, h=1, \ldots, n-1$. Hence, kids 1 and $n$ possess the highest and lowest initial income levels, respectively. Kid $i$ 's budget constraint is

\footnotetext{
${ }^{9}$ When we consider settings in which the kids are homogeneous, we adopt the following convention for partial derivatives: $\partial u / \partial c_{i} \equiv \partial u\left(c_{i}, G, Q\right) / \partial c_{i}, \partial u / \partial G \equiv \partial u\left(c_{i}, G, Q\right) / \partial G, \partial u / \partial Q \equiv \partial u\left(c_{i}, G, Q\right) / \partial Q$. When we consider settings in which the kids are (possibly) heterogeneous, we simply let $u_{c}^{i} \equiv \partial u^{i} / \partial c_{i}, u_{G}^{i} \equiv \partial u^{i} / \partial G, u_{Q}^{i} \equiv \partial u^{i} / \partial Q$.
} 


$$
c_{i}+g_{i}+q_{i}=y_{i}+t_{i},
$$

where $t_{i}$ is the amount of income transfer kid $i$ receives (if positive) or pays (if negative). We assume that the income transfers are redistributive; hence, ${ }^{10}$

$$
\sum_{j=1}^{n} t_{j}=0 .
$$

\subsubsection{Action leadership by parent}

Consider the PLG. All kids observe the parent's income transfers, $\left\{t_{1}, \ldots, t_{n}\right\}$, and in the last stage kid $i$ chooses non-negative $\left\{g_{i}, q_{i}\right\}$ to maximize $u\left(y_{i}+t_{i}-g_{i}-q_{i}, g_{i}+G_{-i}, q_{i}+Q_{-i}\right)$, taking the choices of all other kids as given. Note $G_{-i}=\sum_{h \neq i}^{n} g_{h}$ and $Q_{-i}=\sum_{h \neq i}^{n} q_{h}$. The first order conditions yield, for $i=1, \ldots, n$ :

$$
\begin{gathered}
\frac{\partial u / \partial G}{\partial u / \partial c_{i}} \leq 1, \quad \text { with equality if } g_{i}>0 \\
\frac{\partial u / \partial Q}{\partial u / \partial c_{i}} \leq 1, \quad \text { with equality if } q_{i}>0
\end{gathered}
$$

Throughout, we assume that the Nash equilibria for the contributions' game are interior whenever the kids possess identical utilities; namely, $g_{i}>0$ and $q_{i}>0, \forall i$. Hence, conditions (9) and (10) hold as equalities, $\forall i$ :

$$
\begin{aligned}
& \frac{\partial u / \partial G}{\partial u / \partial c_{i}}=1, \\
& \frac{\partial u / \partial Q}{\partial u / \partial c_{i}}=1 .
\end{aligned}
$$

Equations (7), (11) and (12) yield kid $i$ 's best response functions, $g^{i}\left(t_{1}, \ldots, t_{n}\right)$ and $q^{i}\left(t_{1}, \ldots, t_{n}\right)$, $i=1, \ldots, n$. Let $G\left(t_{1}, \ldots, t_{n}\right)=\sum_{j=1}^{n} g^{j}\left(t_{1}, \ldots, t_{n}\right)$ and $Q\left(t_{1}, \ldots, t_{n}\right)=\sum_{j=1}^{n} q^{j}\left(t_{1}, \ldots, t_{n}\right)$.

\footnotetext{
${ }^{10}$ We assume throughout that the parent does not have any income of her own when the kids are economically independent. Adding an extra source of income to the model would not change the qualitative results.
} 
Before we consider the parent's maximization problem, it is important to note that equations (11) and (12) imply $c_{h}=c_{h+1}, h=1, \ldots, n-1 .{ }^{11}$ Utilizing the redistributive constraint (8), we obtain, for $i=1, \ldots, n$ :

$$
c_{i}\left(t_{1}, \ldots, t_{n}\right)=\frac{Y-G\left(t_{1}, \ldots, t_{n}\right)-Q\left(t_{1}, \ldots, t_{n}\right)}{n},
$$

Conditions (13) informs us that each kid's private-good consumption level equals the family's average disposable income level, where the disposable income level is the difference between total income and total expenditures in the provision of the public goods. Condition (13) implies that the kids’ payoffs are equalized in equilibrium. Hence, we can write, for $i=1, \ldots, n$ :

$$
u^{i}=u\left(\frac{Y-G(.)-Q(.)}{n}, G(.), Q(.)\right) .
$$

The parent anticipates the kids' actions and hence knows that all kids enjoy payoff (14). She chooses $\left\{t_{1}, \ldots, t_{n}\right\}$ to maximize $n u\left(\frac{Y-G(.)-Q(.)}{n}, G(),. Q().\right)$. The first order conditions yield, for $i=1, \ldots, n$ :

$$
\frac{\partial G}{\partial t_{i}}\left(-u_{c}+n u_{G}\right)+\frac{\partial Q}{\partial t_{i}}\left(-u_{c}+n u_{Q}\right)=0
$$

Since equations (11) and (12) imply $n u_{G} / u_{c}=n$ and $n u_{Q} / u_{c}=n$, respectively, conditions (15) can be rewritten as follows, for $i=1, \ldots, n$ :

$$
(n-1) \frac{\partial u}{\partial c}\left(\frac{\partial G}{\partial t_{i}}+\frac{\partial Q}{\partial t_{i}}\right)=0 \Rightarrow \frac{\partial G}{\partial t_{i}}+\frac{\partial Q}{\partial t_{i}}=0
$$

Conditions (16) show that the equilibrium levels for the public goods do not change under any income redistribution scheme implemented by the parent. As demonstrated by Cornes and Itaya (2010), Warr’s (1983) 'policy neutrality’ result also holds in settings with multiple public goods. The income transfer mechanism, however, may guarantee that all kids have enough income in order to make positive contributions to the public goods. To see this, suppose that all kids make identical contributions to both public goods in equilibrium: $g_{i}=G / n$ and $q_{i}=Q / n, \forall i$. Since

\footnotetext{
${ }^{11}$ For $u^{i}=\alpha \ln c_{i}+\beta \ln G+(1-\alpha-\beta) \ln Q$, we have $u_{G}^{i} / u_{c}^{i}=\beta c_{i} / \alpha G$ and $u_{Q}^{i} / u_{c}^{i}=(1-\alpha-\beta) c_{i} / \alpha Q$. Hence, $u_{G}^{h} / u_{c}^{h}=u_{G}^{h+1} / u_{c}^{h+1}$ and $u_{Q}^{h} / u_{c}^{h}=u_{Q}^{h+1} / u_{c}^{h+1}$ imply $c_{h}=c_{h+1}, h=1, \ldots, n-1$.
} 
$c_{i}=y_{i}+t_{i}-g_{i}-q_{i}$ and $c_{i}=(Y-G-Q) / n$, we have $t_{i}=\left(Y-n y_{i}\right) / n$. In this case, if kid $i$ 's initial income level is above (below) the family's average income level, $t_{i}<(>) 0$.

\subsubsection{Action leadership by kids}

Now, consider the KLG. The parent observes $\left\{g_{1}, \ldots, g_{n}, q_{1}, \ldots, q_{n}\right\}$ and in the last stage chooses $\left\{t_{1}, \ldots, t_{n}\right\}$ to maximize $W=\sum_{j=1}^{n} u^{j}$ subject to (8). This problem is equivalent to choosing nonnegative $\left\{c_{1}, \ldots, c_{n}\right\}$ to maximize $W=\sum_{j=1}^{n} u^{j}$ subject to (1) (see, e.g., Silva (2014)). Letting $\lambda \geq 0$ denote the multiplier associated with the family's resource constraint, the first order conditions are given by equations (2), for $i=1, \ldots, n$. These conditions, in turn, imply that $c_{h}=c_{h+1}, h=1, \ldots, n-1$ . Hence, for $i=1, \ldots, n$ :

$$
c^{i}(G, Q)=\frac{Y-G-Q}{n}
$$

where $c^{i}(),. i=1, \ldots, n$, are the parent's best response functions. They yield each kid's privategood consumption level in the last stage of the KLG. Plugging (17) in kid $i$ 's payoff we obtain, for $i=1, \ldots, n$ :

$$
u^{i}=u\left(\frac{Y-g_{i}-G_{-i}-q_{i}-Q_{-i}}{n}, g_{i}+G_{-i}, q_{i}+Q_{-i}\right) \text {. }
$$

Anticipating the parent's choices and the outcome produced by her choices, kid $i$ chooses non-negative $\left\{g_{i}, q_{i}\right\}$ to maximize (18). Assuming an interior solution, the first order conditions yield

$$
\begin{aligned}
& n \frac{\partial u / \partial G}{\partial u / \partial c}=1, \\
& n \frac{\partial u / \partial Q}{\partial u / \partial c}=1 .
\end{aligned}
$$

Equations (19) and (20) are the Samuelson conditions for optimal provision of the public goods. The SPNE for the KLG satisfies conditions (1), (2), (19) and (20). 


\subsubsection{Optimal Timing Decision}

We now examine the first stage of the family's supergame. The results above show that the SPNE for the PLG is inefficient (not first best) and that the SPNE for the KLG is first best. Hence, in the first stage of the family's supergame, the parent strictly prefers the KLG to the PLG. We summarize the SPNE for the family's supergame as follows:

Proposition 1 (SPNE for Supergame with Homogeneous Kids and Parental Control of Income Transfers). In the SPNE for the family's supergame with income transfers, the parent chooses the KLG in the first stage. The kids and the parent subsequently play the KLG. The SPNE for the supergame is first best.

\subsection{Parent controls each kid's private-good consumption}

We now analyze the setting where the parent controls each kid's private-good consumption.

\subsubsection{Action leadership by parent}

In the last stage, having observed $\left\{c_{1}, \ldots, c_{n}\right\}$, kid $i$ chooses non-negative $\left\{g_{i}, q_{i}\right\}$ to maximize $u\left(c_{i}, g_{i}+G_{-i}, q_{i}+Q_{-i}\right)$ subject to (1), taking the other kids’ choices as given. Let

$$
q_{i}=Y-C-G-Q_{-i}, \quad i=1, \ldots, n,
$$

where $\quad C=\sum_{h=1}^{n} c_{h}$. Given (21), kid $i$ chooses non-negative $g_{i}$ to maximize $u\left(c_{i}, g_{i}+G_{-i}, Y-C-g_{i}-G_{-i}\right)$. Assuming an interior solution, the first order condition yields, for $i=1, \ldots, n$ :

$$
\frac{\partial u / \partial G}{\partial u / \partial Q}=1
$$

Since $\partial^{2} u / \partial Q^{2}<0$, equation (22) enables us to implicitly define $Q$ as an increasing function of $G: Q=Q(G)$. However, in order to provide intuition, we carry out the following analysis for $u^{i}=\alpha \ln c_{i}+\beta \ln G+(1-\alpha-\beta) Q$. Equation (22) implies

$$
Q=\chi G,
$$


where $\chi \equiv(1-\alpha-\beta) / \beta>0$. Combining equation (23) with equation (1) yields

$$
G(C)=\frac{Y-C}{1+\chi}
$$

Combining equations (23) and (24), we have

$$
Q(C)=\chi G(C) \text {. }
$$

Anticipating the last stage's actions and outcome, the parent chooses non-negative

$\left\{c_{1}, \ldots, c_{n}\right\}$ to maximize $\sum_{j=1}^{n} u\left(c_{j}, G(C), Q(C)\right)$. The first order conditions are as follows, for $i=1, \ldots, n$ :

$$
\frac{\partial u}{\partial c_{i}}+\sum_{j=1}^{n}\left(\frac{\partial u}{\partial G} \frac{d G}{d C}+\frac{\partial u}{\partial Q} \frac{d Q}{d C}\right)=0 .
$$

Conditions (26) imply that $\partial u / \partial c_{i}=\partial u / \partial c_{h}, h, i=1, \ldots, n, h \neq i$. Combining equations (24) - (26) yields, for $i=1, \ldots, n$ :

$$
\frac{\partial u}{\partial c_{i}}-\frac{1}{1+\chi} \sum_{j=1}^{n}\left(\frac{\partial u}{\partial G}+\chi \frac{\partial u}{\partial Q}\right)=0 .
$$

Combining equations (22) and (27), we obtain, for $i=1, \ldots, n$ :

$$
\sum_{j=1}^{n} \frac{\partial u / \partial G}{\partial u / \partial c_{i}}=1=\sum_{j=1}^{n} \frac{\partial u / \partial Q}{\partial u / \partial c_{i}} .
$$

Equations (28) are the Samuelson conditions for optimal provision of the public goods. The SPNE for the PLG satisfies equations (1), (2) and (28). It is, therefore, first best.

\subsubsection{Action leadership by kids}

The SPNE for the KLG when the parent controls private-good consumption for each kid is identical to the SPNE for the KLG when the parent controls income transfers. This follows from the fact that in the KLG in which the parent controls income transfers the parent determines each kid's private-good consumption in the last stage of the KLG. This is exactly what happens when she controls each kid's private-good consumption. Given the equivalence between the SPNE for the KLG under parental control of income transfers and the KLG under parental control of each kid's private-good consumption level, we can state that the SPNE for the KLG under parental control of each kid's private-good consumption is also first best. 


\subsubsection{Optimal Timing Decision}

The results we have obtained in the setting where the parent controls each kid's private-good consumption enable us to conclude that in the first stage of the family's supergame the parent is indifferent between the PLG and K LG, since the SPNE for each type of game is first best. Hence, we can state:

Proposition 2 (SPNE for the Supergame with Homogeneous Kids and Parental Control of Kids' Private-Good Consumption). The SPNE for the family's supergame when the parent controls each kid's private-good consumption involves either the choice of PLG or the KLG in the first stage. The SPNE for the family’s supergame is first best.

\subsection{Rotten kid theorem: Omnipresent with homogeneous kids}

Propositions 1 and 2 imply that the parent strictly prefers to be a follower when she controls income transfers and she is indifferent between being a leader or a follower when she controls each kid's private-good consumption. Parental leadership is optimal only if the parent controls each kid's private-good consumption, since in this situation parental policy is non-neutral and the SPNE is first best. If the parent is obliged to choose between being an action leader or follower irrespective of the type of instrument (income transfers or private-good consumption levels) that she possesses, she will prefer to be a follower.

\section{Supergames with Heterogeneous Kids}

We now consider the family's supergame in settings where the kids have different preferences. Without loss of generality, we assume that $u_{G}^{h}>u_{G}^{h+1}$ and $u_{Q}^{h}>u_{Q}^{h+1}, h=1, \ldots, n-1$. These assumptions imply that kid 1 possesses the highest marginal utilities of consumption of public goods. Even though the kids have different marginal utilities of consumption of public goods, we will consider situations where all of them agree about the tradeoff between the two public goods. There is common agreement about the tradeoff between the two public goods if and only if, for $i, j=1, \ldots, n, i \neq j$ : 


$$
\frac{u_{Q}^{i}}{u_{G}^{i}}=\frac{u_{Q}^{j}}{u_{G}^{j}} .
$$

As it should be clear in what follows, condition (29) is necessary for interior Nash equilibria in the

PLG. For the sake of clarity, we will let $u^{i}=\alpha_{i} \ln c_{i}+\beta_{i} \ln G+\left(1-\alpha_{i}-\beta_{i}\right) \ln Q$ in what follows.

The assumption about marginal utilities imply $\beta^{h}>\beta^{h+1}, \alpha^{h+1}+\beta^{h+1}>\alpha^{h}+\beta^{h}, h=1, \ldots, n-1$. These two inequalities, in turn, imply $\alpha^{h+1}>\alpha^{h}, h=1, \ldots, n-1$. Restriction (29) implies that, for $i, j=1, \ldots, n, i \neq j:$

$$
\frac{1-\alpha_{i}-\beta_{i}}{\beta_{i}}=\frac{1-\alpha_{j}-\beta_{j}}{\beta_{j}} .
$$

Even condition (30) appears to be strong, it is important to notice that it permits several combinations of taste parameters. Consider, for example, a family with three kids, where the utilities of kids 1,2 and 3 have the following taste parameters, respectively: $\left(\alpha_{1}, \beta_{1}\right)=(0.1,0.3)$, $\left(\alpha_{2}, \beta_{2}\right)=(0.4,0.2) \quad$ and $\quad\left(\alpha_{3}, \beta_{3}\right)=(0.7,0.1)$. Letting $\quad \chi_{i} \equiv\left(1-\alpha_{i}-\beta_{i}\right) / \beta_{i}$, we have $\chi_{1}=\chi_{2}=\chi_{3}=2$.

\subsection{Parent controls income transfers}

We again examine both PLG and KLG, determine the equilibria and later compare the implied family welfare levels.

\subsubsection{Action leadership by parent}

Consider the last stage of the PLG. Having observed $\left\{t_{1}, \ldots, t_{n}\right\}$, kid $i$ chooses non-negative $\left\{g_{i}, q_{i}\right\}$ to maximize $u^{i}\left(y_{i}+t_{i}-g_{i}-q_{i}, g_{i}+G_{-i}, q_{i}+Q_{-i}\right)$. If $g_{i}>0$ and $q_{i}>0, \forall i$, in equilibrium, the first order conditions are as follows, for $\forall i$ :

$$
\begin{aligned}
& \frac{u_{G}^{i}}{u_{c}^{i}}=\frac{\beta_{i} c_{i}}{\alpha_{i} G}=1, \\
& \frac{u_{Q}^{i}}{u_{c}^{i}}=\frac{\left(1-\alpha_{i}-\beta_{i}\right) c_{i}}{\alpha_{i} Q}=1 .
\end{aligned}
$$


Restriction (30) is a necessary condition for equations (31) and (32) to hold simultaneously, for $i=1, \ldots, n$.

Assume that $\chi_{i} \equiv \chi_{j} \equiv \chi, \forall i, j, i \neq j$. Then, the equilibrium in the last stage satisfies equations (7), (31) and (32). Letting $g^{i}\left(t_{1}, \ldots, t_{n}\right)$ and $q^{i}\left(t_{1}, \ldots, t_{n}\right)$ denote kid $i$ 's best response functions, $i=1, \ldots, n$, we have $G\left(t_{1}, \ldots, t_{n}\right)=\sum_{j=1}^{n} g^{j}\left(t_{1}, \ldots, t_{n}\right)$ and $Q\left(t_{1}, \ldots, t_{n}\right)=\sum_{j=1}^{n} q^{j}\left(t_{1}, \ldots, t_{n}\right)$. From equations (31) and (32), we know that, for $i=1, \ldots, n$ :

$$
c^{i}\left(t_{1}, \ldots, t_{n}\right)=\frac{\alpha_{i} G\left(t_{1}, \ldots, t_{n}\right)}{\beta_{i}}=\frac{\alpha_{i} Q\left(t_{1}, \ldots, t_{n}\right)}{1-\alpha_{i}-\beta_{i}} .
$$

Equations (33) yield, for $i=1, \ldots, n$ :

$$
Q\left(t_{1}, \ldots, t_{n}\right)=\chi G\left(t_{1}, \ldots, t_{n}\right) .
$$

Equations (32) and (33) imply that we can write kid $i$ 's payoff as follows, for $i=1, \ldots, n$ :

$$
u^{i}\left(t_{1}, \ldots, t_{n}\right)=\ln G\left(t_{1}, \ldots, t_{n}\right)+\gamma_{i}
$$

where $\gamma_{i} \equiv \alpha_{i}\left(\ln \alpha_{i}-\ln \beta_{i}\right)+\left(1-\alpha_{i}-\beta_{i}\right) \ln \chi$. Equation (35) is remarkable. Since $\gamma_{i}$ is a constant, it informs us that all kids’ incentives are perfectly aligned.

Anticipating the last stage's actions and outcome, the parent knows that (35) holds. Hence, she wishes to maximize $n G\left(t_{1}, \ldots, t_{n}\right)$ subject to (8). Since (8) implies (1), we can combine (1) with equations (33) and (34) to obtain

$$
G\left(t_{1}, \ldots, t_{n}\right)=Y\left[1+\chi+\sum_{j=1}^{n} \sigma_{j}\right]^{-1},
$$

where $\sigma_{j} \equiv \alpha_{j} / \beta_{j}$. Condition (36) implies that $\partial G / \partial t_{i}=0, \forall i$. Alternatively, one can substitute (36) into the parent's payoff and then notice that the implied expression is a constant, independent of the income transfers. Once again, we obtain the policy neutrality result in the SPNE for the PLG where the parent controls income transfers.

In addition to (36), the SPNE for the PLG yields the following allocation:

$$
Q=\chi Y\left[1+\chi+\sum_{j=1}^{n} \sigma_{j}\right]^{-1}
$$




$$
\begin{array}{ll}
C=Y \sum_{j=1}^{n} \sigma_{j}\left[1+\chi+\sum_{j=1}^{n} \sigma_{j}\right]^{-1}, & \\
C_{i}=\sigma_{i} Y\left[1+\chi+\sum_{j=1}^{n} \sigma_{j}\right]^{-1} . & i=1, \ldots, n .
\end{array}
$$

\subsubsection{Action leadership by kids}

The parent observes $\left\{g_{1}, \ldots, g_{n}, q_{1}, \ldots, q_{n}\right\}$ and then chooses $\left\{t_{1}, \ldots, t_{n}\right\}$ to maximize $\sum_{j=1}^{n} u^{j}$ subject to (8) in the last stage. But, as we noted before, this is equivalent to choosing non-negative $\left\{c_{1}, \ldots, c_{n}\right\}$ to maximize $\sum_{j=1}^{n} u^{j}$ subject to (1). Letting $\lambda \geq 0$, the first order conditions are as follows, for $i=1, \ldots, n:$

$$
u_{c}^{i}=\alpha_{i} c_{i}^{-1}=\lambda .
$$

Conditions (40) imply

$$
c_{h}=\frac{\alpha_{h} c_{i}}{\alpha_{i}}, \quad \forall h \neq i .
$$

Combining equations (41) and (1) yields, for $i=1, \ldots, n$ :

$$
c_{i}=\frac{\alpha_{i}(Y-G-Q)}{A} \text {, }
$$

where $A \equiv \sum_{j=1}^{n} \alpha_{j}$. Plugging (42) into kid i's payoff, we have

$$
u^{i}\left(\frac{\alpha_{i}\left(Y-g_{i}-G_{-i}-q_{i}-Q_{-i}\right)}{A}, g_{i}+G_{-i}, q_{i}+Q_{-i}\right), \quad i=1, \ldots, n .
$$

Anticipating the parent's actions and their resulting outcome, kid $i$ chooses non-negative $\left\{g_{i}, q_{i}\right\}$ to maximize (43). It is straightforward to show that, in equilibrium, the sole provider of both public goods is kid 1 . This follows from the facts that this kid has the highest marginal utilities of consumption of public goods and the parent's choices in the last stage equate the marginal utilities of private-good consumption (see equation (40)). Hence, $g_{1}>0, q_{1}>0$ and $g_{h}=q_{h}=0$, $h=2, \ldots, n$. The conditions that determine the equilibrium levels of the public goods are 


$$
\begin{aligned}
& \frac{u_{G}^{1}}{u_{c}^{1}}=\frac{\beta_{1} c_{1}}{\alpha_{1} G}=\frac{\alpha_{1}}{A} \Rightarrow \quad\left(\alpha_{1}+\beta_{1}\right) G+\beta_{1} Q=\beta_{1} Y . \\
& \frac{u_{Q}^{1}}{u_{c}^{1}}=\frac{\left(1-\alpha_{1}-\beta_{1}\right) c_{1}}{\alpha_{1} Q}=\frac{\alpha_{1}}{A} \Rightarrow \quad\left(1-\alpha_{1}-\beta_{1}\right) G+\left(1-\beta_{1}\right) Q=\left(1-\alpha_{1}-\beta_{1}\right) Y .
\end{aligned}
$$

Solving the system of equations (44) - (45), we have

$$
\begin{aligned}
& G=\beta_{1} Y . \\
& Q=\left(1-\alpha_{1}-\beta_{1}\right) Y .
\end{aligned}
$$

Combining equations (46) and (47) with the family's resource constraint (1) yields

$$
C=\alpha_{1} Y \text {. }
$$

Combining equations (42) and (48), we obtain

$$
c_{i}=\frac{\alpha_{i} \alpha_{1} Y}{A}, \quad i=1, \ldots, n .
$$

The solution to kid 1's problem, described by equations (46)-(48), demonstrates that this kid behaves as a "dictator" in the KLG, since the final allocation of resources corresponds to this kid's most preferred allocation. Conditions (49) inform us how the parent allocates the total amount of disposable income (determined by condition (48)) across the kids. The SPNE for the KLG is not first best because it does not satisfy the Samuelson conditions for optimal provision of the public goods.

\subsubsection{Optimal Timing Decision}

Let us now consider the first stage of the family's supergame. Let $W^{P}$ and $W^{K}$ denote the family welfare levels implied by the PLG and KLG, respectively. Close inspection of the conditions that display the equilibrium quantities (i.e., (36) - (39) for the PLG and (46) - (49) for the KLG) reveals that the welfare levels depend on the taste parameters and on family size. Suppose that $n=2$. Consider the differences in payoffs for each kid:

$$
\begin{aligned}
u^{1 K}-u^{1 P}= & \alpha_{1}\left(\ln \alpha_{1}-\ln \left(\alpha_{1}+\alpha_{2}\right)\right)+\ln \beta_{1}+\ln (1+\omega), \\
u^{2 K}-u^{2 P}= & \alpha_{2}\left(\ln \alpha_{1}-\ln \left(\alpha_{1}+\alpha_{2}\right)\right)+\ln \beta_{2}+\ln (1+\omega) \\
& +\beta_{2}\left(\ln \beta_{1}-\ln \beta_{2}\right)+\left(1-\alpha_{2}-\beta_{2}\right)\left(\ln \left(1-\alpha_{1}-\beta_{1}\right)-\ln \left(1-\alpha_{2}-\beta_{2}\right)\right),
\end{aligned}
$$


where $\omega \equiv \chi+\sigma_{1}+\sigma_{2}, u^{i K}$ and $u^{i p}$ are the payoffs enjoyed by kid $i, i=1,2$, in the subgame perfect Nash equilibria for the KLG and PLG, respectively. Consider equation (50). Since $\alpha_{1}<1$, the first term in the right hand side is negative. Similarly, since $\beta_{1}<1$, the second term in the right hand side is also negative. But, the last term in the right hand is positive because $\omega>0$. Consider the right hand side of equation (51). Except for the first two terms, all other terms are positive.

We now show that the comparison between welfare levels is ambiguous. Consider the following two examples: (i) $\left(\alpha_{1}, \beta_{1}\right)=(0.1,0.3) ;\left(\alpha_{2}, \beta_{2}\right)=(0.4,0.2) ; \chi=2 ; \sigma_{1}=0.33 ; \sigma_{2}=2$; $\omega=4.33$; and (ii) $\left(\alpha_{1}, \beta_{1}\right)=(0.1,0.18) ;\left(\alpha_{2}, \beta_{2}\right)=(0.11,0.178) ; \chi=4 ; \sigma_{1}=0.56 ; \sigma_{2}=0.62$; $\omega=5.18$. Example (i) yields $u^{1 K}-u^{1 P}=0.31$ and $u^{2 K}-u^{2 P}=-0.34$. Hence, $W^{P}>W^{K}$ in this case. Example (ii) yields $u^{1 K}-u^{1 P}=0.04$ and $u^{2 K}-u^{2 P}=0.02$. Hence, $W^{K}>W^{P}$ in this case. A critical difference between the two examples is the degree of heterogeneity, measured by the “distances" between $\left(\alpha_{1}, \beta_{1}\right)$ and $\left(\alpha_{2}, \beta_{2}\right):\left(\alpha_{1}-\alpha_{2}\right)^{2}$ and $\left(\beta_{1}-\beta_{2}\right)^{2}$. The degree of heterogeneity is larger in the first example. Intuitively, the lower the degree of heterogeneity, the more likely it is that the SPNE for the KLG dominates the SPNE for the PLG (and vice-versa). In the limit, when the distance between parameters are nil and we find ourselves in the situation where the kids are homogeneous, we have the result of the previous section where the KLG always dominates the PLG when the parent controls income transfers.

\subsection{Parent controls each kid's private-good consumption}

Suppose now that the parent controls each kid's private-good consumption. We determine the equilibria for the PLG and KLG and later compare the implied welfare levels.

\subsubsection{Action leadership by parent}

Kid $i$ observes $\left\{c_{1}, \ldots, c_{n}\right\}$ and then chooses non-negative $\left\{g_{i}, q_{i}\right\}$ to maximize $u^{i}\left(c_{i}, g_{i}+G_{-i}, q_{i}+Q_{-i}\right)$ subject to (21). Using constraint (21), kid $i$ 's problem becomes the choice of non-negative $g_{i}$ to maximize $u^{i}\left(c_{i}, g_{i}+G_{-i}, Y-C-g_{i}-G_{-i}\right)$. Assuming that $g_{i}>0$, in equilibrium, the first order condition yields: 


$$
\frac{u_{G}^{i}}{u_{Q}^{i}}=\frac{\beta_{i} Q}{\left(1-\alpha_{i}-\beta_{i}\right) G}=1 \quad \Rightarrow \quad Q=\chi G \quad i=1, \ldots, n .
$$

Combining equations (21) and (52) yield equation (24), which then yields (25) by plugging (24) into (52).

Anticipating the last stage's actions and outcome, the parent chooses non-negative $\left\{c_{1}, \ldots, c_{n}\right\}$ to maximize $\sum_{j=1}^{n} u^{j}\left(c_{j}, G(C), Q(C)\right)$. The first order conditions are as follows, for $i=1, \ldots, n$ :

$$
u_{c}^{i}+\sum_{j=1}^{n}\left(u_{G}^{j} \frac{d G}{d C}+u_{Q}^{j} \frac{d Q}{d C}\right)=0 .
$$

Conditions (53) imply that $u_{c}^{i}=u_{c}^{h}, h, i=1, \ldots, n, h \neq i$. Combining equations (24), (25) and (53) yields, for $i=1, \ldots, n$ :

$$
u_{c}^{i}-\frac{1}{1+\chi} \sum_{j=1}^{n}\left(u_{G}^{i}+\chi u_{Q}^{i}\right)=0 .
$$

Combining equations (52) and (54), we obtain, for $i=1, \ldots, n$ :

$$
\begin{aligned}
& u_{c}^{i}-\frac{1}{1+\chi} \sum_{j=1}^{n}\left(u_{G}^{i}(1+\chi)\right)=0 \Rightarrow u_{c}^{i}-\sum_{j=1}^{n} u_{G}^{i}=0 \Rightarrow \sum_{j=1}^{n} \frac{u_{G}^{i}}{u_{c}^{i}}=1, \\
& u_{c}^{i}-\frac{1}{1+\chi} \sum_{j=1}^{n}\left(u_{Q}^{i}(1+\chi)\right)=0 \Rightarrow u_{c}^{i}-\sum_{j=1}^{n} u_{Q}^{i}=0 \Rightarrow \sum_{j=1}^{n} \frac{u_{Q}^{i}}{u_{c}^{i}}=1 .
\end{aligned}
$$

Equations (55) and (56) are the Samuelson conditions for optimal provision of the public goods. The SPNE satisfies conditions (1), (2), (55) and (56). Hence, it is first best.

\subsubsection{Action leadership by kids}

As in the subsection 3.1.2, one should notice that the KLG under parental control of private-good consumption levels is isomorphic to the KLG under parental control of income transfers. Hence, the SPNE for the KLG under parental control of private-good consumption levels is identical to the SPNE for the KLG under parental control of income transfers. 


\subsubsection{Optimal Timing Decision}

In the first stage of the family's supergame, the parent chooses the PLG because its subgame perfect Nash equilibrium is first best, while the SPNE for the KLG is not first best. In sum,

Proposition 3 (SPNE for Supergame with Heterogeneous Kids and Parental Control of Kids' Private-Good Consumption). In the SPNE for the family's supergame in which the parent controls each kid's private-good consumption, the parent chooses the PLG in the first stage. The kids and the parent subsequently play the PLG. The SPNE for the supergame is first best.

\subsection{Parental leadership: Dominance under large heterogeneity}

The results in this section clearly show that parental leadership dominates kids' leadership for sufficiently large degree of heterogeneity irrespective of the type of parental control over resources. The fact that parental leadership is always preferable under parental control of kids' private-good consumption level is reassuring, since this is what we typically observe in reality. The fact that parental leadership is also preferable under sufficiently large degree of heterogeneity under parental control of income transfers is, at first glance, counter-intuitive because the parental income-transfer policy in this regime is neutral. The reason why the result holds is that in the alternative setting, with kids being action leaders, the equilibrium outcome reflect the dictator's preferences. Hence, the more diverse the kid population is with respect to preferences, the lower the family welfare that is produced under this regime.

\section{Conclusion}

This paper is a primer in the literature in that the timing of the sequential-action game played by parent and rotten kids is endogenous. It also advances the literature by considering alternative instruments for the parent, consistent with the degree of economic dependence of the kids, and by examining the provision of multiple public goods in sequential-action games in the presence of heterogeneous preferences. The messages that we obtain in the analysis are important in terms of policy implications and potential understanding of why some families have leading parents while some other families have parents who follow. For families where kids are homogeneous, or nearly 
so, it is rational for the parent to be a follower in the sequential-action game. For families whose kids are sufficiently heterogeneous, however, it is rational for parents to be action leaders.

\section{References}

Amir, R. and A. Stepanova, 2006. Second-mover advantage and price leadership in Bertrand duopoly, Games and Economic Behavior 55, 1-20.

Arce, D., 2001. Leadership and the aggregation of international collective action, Oxford Economic Papers 53, 114-137.

Arce, D., 2004. Asymmetric leadership and international public goods, Public Finance Review 32, 528-558.

Becker, G. S., 1974. A theory of social interactions, Journal of Political Economy 82, 1063-93

Becker, G. S., 1976. Altruism, egoism, and genetic fitness: economics and sociobiology," Journal of Economic Literature 14, 817-826.

Becker, G. S., 1977. Reply to Hirshleifer and Tullock, Journal of Economic Literature 15, 506507.

Becker, G. S., 1981. A treatise on the family. Cambridge, Mass. Harvard University Press.

Bergstrom, T., 1989. A fresh look at the rotten kid theorem - and other household mysteries, Journal of Political Economy 97, 1138-1159.

Bergstrom, T., 2008. Rotten kid theorem. The New Palgrave Dictionary of Economics (2nd ed.).

Bruce, N. and M. Waldman, 1990. The rotten-kid theorem meets the Samaritan's Dilemma. Quarterly Journal of Economics 105, 155-65.

Buchanan, J. M., 1975. The Samaritan's Dilemma, in Altruism, Morality and Economic Theory, Edmund S. Phelps, ed. (New York: Russell Sage Foundation, 1975), pp. 71-85.

Caplan, A., R.C. Cornes and E.C.D. Silva, 2000. Pure public goods and income redistribution in a federation with decentralized leadership and imperfect labor mobility, Journal of Public Economics 77, 265-284.

Chiappori, P.A. and I. Werning, 2002. Comment on Rotten kids, purity, and perfection, Journal of Political Economy 110, 475-480.

Coate, S., 1995. Altruism, the Samaritan's dilemma, and government transfer policy, American Economic Review 85, 46-57. 
Cornes, R.C. and J-I Itaya, 2010. On the private provision of two or more public goods, Journal of Public Economic Theory 12, 363-385.

Cornes, R.C., J-I Itaya and A. Tanaka, 2012. Private provision of public goods between families, Journal of Population Economics 25, 1451-1480.

Cornes, R.C. and E.C.D. Silva, 1999. Rotten kids, purity and perfection, Journal of Political Economy 107, 1034-1040.

Cremer, H. and K. Roeder, 2017. Rotten spouses, family transfers, and public goods, Journal of Population Economics 30, 141-161.

Dowrick, S., 1986. von Stackelberg and Cournot duopoly: Choosing roles, Rand Journal of Economics 17, 251-260.

Gale-Or, E., 1985. First mover and second mover advantages, International Economic Review 26, 649-653.

Gintis, H., 2009. Game Theory Evolving, Princeton University Press, Princeton.

Hamilton, J.H. and S.M. Slutsky, 1990. Endogenous timing in duopoly games: Stackelberg or Cournot equilibria, Games and Economic Behavior 2, 29-46.

Kindleberger, C.P., 1981. Dominance and leadership in the international economy. Exploitation, public goods, and free rides, International Studies Quarterly 25, 242-254.

Kotlikoff, Laurence J. 1987. Justifying public provision of social security, Journal of Policy Analysis and Management 6, 674-89.

Lafferrere, A. and F.-C. Wolff, 2006. Microeconomic models of family transfers. In: Kolm, S.-C. and J.M. Ythier (eds) Handbook of the economics of giving, altruism and reciprocity, vol 1., Elsevier, Amsterdam, pp 879-969.

Lindbeck, A. and J. Weibull, 1988. Altruism and efficiency: the economics of fait accompli, Journal of Political Economy 96, 1165-82.

Lundberg, S. and R. Pollak, 2003. Efficiency in marriage, Review of the Economics of the Household 1, 153-67.

Oliveira, A., J.R. Faria and D. Arce., 2005. Leading by example and international collective action, Journal of Public Economic Theory 7, 51-63.

Silva, E.C.D., 2014. Selective decentralized leadership, Journal of Urban Economics 83, 1-5.

Silva, E.C.D., 2016. Decentralized leadership, CESIfo Working Paper, No. 6064. 
Silva, E.C.D. and V.M. Lucas, 2016. Common labor market, attachment and spillovers in a large metropolis, International Tax and Public Finance 23, 693-715.

Thompson, E. A., 1980. Charity and nonprofit organizations, in Economics of Nonproprietary Organizations, K. Clarkson and D. Martin, eds. (Greenwich, CT: JAI Press, Inc. 1980), pp. 125-38.

Tuchman Matthews, J., 1991. Preserving the global environment. The challenge of joint leadership. NY: Norton

Wagner, R. E., 1965. Pressure groups and political entrepreneurs: A review article, Papers on NonMarket Decision Making 1, 161-170.

Warr, P., 1983. The private provision of a public good is independent from the distribution of income, Economics Letters 13, 207-211. 